\title{
WHO Follicular Lymphoma Histologic Grading System
}

National Cancer Institute

\section{Source}

National Cancer Institute. WHO Follicular Lymphoma Histologic Grading System. NCI

Thesaurus. Code C162997.

A grading system for follicular lymphoma based on the average number of large transformed cells in 10 neoplastic follicles at 40x high-power field. 